\title{
Canadian College of Neuropsychopharmacology 2017 award winners
}

\section{Heinz Lehmann Award}

Dr. Paul Albert is the recipient of the 2017 CCNP Heinz Lehmann Award. Dr. Albert obtained his PhD in Pharmacology from Harvard University (1985) and completed postdoctoral studies with Drs. Herbert and Civelli. He was an Assistant/ Associate Professor at McGill University from 1989 to 1995 and became the Canadian Institutes of Health Research (CIHR)/ Novartis Michael Smith Chair in Neuroscience at the University of Ottawa in 1996, where he has been a Full Professor since 2000, Senior Scientist since 2001, and Associate Director of Neuroscience at the Ottawa Hospital Research Institute since 2006. He is also a past Director of the Neuroscience Graduate Program. This award is designed to recognize outstanding research achievements by Canadian scientists in the field of neuropsychopharmacology, and this year the award is for clinical/ translational research. The award, donated by Pfizer Canada Inc., consists of a $\$ 2000$ honorarium and a suitably engraved plaque. Congratulations to Dr. Albert!

\section{Innovations in Neuropsychopharmacology Award}

Dr. Yu Tian Wang is the recipient of the 2017 CCNP Innovations in Neuropsychopharmacology Award. Dr. Wang is a Professor and the holder of the Heart and Stroke Foundation of B.C. \& Yukon Chair in Stroke Research in the Department of Medicine and the Brain Research Centre at the University of British Columbia. He was also a Howard Hughes Medical Institute International Scholar between 2001 and 2011, and he was elected as a Fellow of the Academy of Sciences of the Royal Society of Canada in 2006. This award is designed to recognize outstanding and innovative research in the basic or clinical fields of neuropsychopharmacology, and this year the award is for clinical/translational research. The award, donated by Pfizer Canada Inc., consists of a \$2000 honorarium and a suitably engraved plaque. Congratulations to Dr. Wang!

\section{Young Investigator Award}

Dr. Lena Palaniyappan is the recipient of the 2017 CCNP Young Investigator Award. Dr. Palaniyappan is a young investigator at the Robarts Research Institute, London, Ontario, and an Associate Professor in the Departments of Psychiatry and Medical Biophysics at Western University. The award, donated by Pfizer Canada Inc., consists of a \$2000 honorarium and a suitably engraved plaque. Congratulations to Dr. Palaniyappan!

\section{CCNP Medal}

Dr. Zul Merali is the recipient of the 2017 CCNP Medal. Dr. Merali is President and CEO of The Royal's Institute of Mental Health Research (IMHR), the hospital's research arm, and is proudly affiliated with the University of Ottawa. He is a Full Professor in the faculties of Medicine (Departments of Cellular and Molecular Medicine and Psychiatry) and Social Sciences (Department of Psychology) at the University of Ottawa. He is also a Research Professor at the Institute of Neuroscience at Carleton University. This award, sponsored by the CCNP, consists of a bronze medal engraved with the name of the recipient. Congratulations to Dr. Merali!

These awards will be conferred at the 40th Annual CCNP Meeting in Kingston, Ontario, June 6-9, 2017. The 2017 conference theme will be "Clinical and Basic Sciences Research Advancing Our Understanding of Brain Function and Treatment Approaches." This meeting will also highlight the work and findings of several integrated discovery programs funded by the Ontario Brain Institute (OBI), followed by a panel discussion involving OBI President, Tom Mikkelsen.

DOI: 10.1503/jpn.170069 